\title{
Predicados nominais em Kaiowá
}

Nominal predicates in Kaiowá language

\author{
Andérbio Márcio Silva MARTINS* \\ Universidade Federal da Grande Dourados (UFGD) \\ Lívia Ribeiro VIEGAS ${ }^{* *}$
}

\begin{abstract}
RESUMO: Neste artigo apresentamos uma proposta de descrição dos predicados nominais da língua Kaiowá, membro do sub-ramo I da família Tupí-Guaraní, segundo Rodrigues (1984/1985). Trata-se, portanto, de um estudo da descrição morfossintática dos nomes nessa língua. A análise encontra-se fundamentada primordialmente em Rodrigues (2001), mas também nos aproximamos e nos sentimos contemplados com as ideias de Payne (1997). Neste texto encontra-se, portanto, uma descrição das propriedades sintáticas dos nomes que ocorrem em função de núcleo de predicado. $\mathrm{O}$ olhar dado à questão nos possibilitou descrever predicados existenciais, equativos e atributivos, ampliando nosso conhecimento acerca desses fenômenos por meio da análise linguística de uma variedade da língua Kaiowá falada no cone sul de Mato Grosso do Sul. Acreditamos que os resultados podem ser comparados com outras línguas TupíGuaraní com o objetivo de buscar possíveis explicações das mudanças ocorridas dentro da família e identificar o que tem sido conservado sob este aspecto.
\end{abstract}

PALAVRAS-CHAVE: Família Tupí-Guaraní. Língua Kaiowá. Predicados Nominais.

\begin{abstract}
In this paper, we present a proposal for the description of the nominal predicates of the Kaiowá language, member of the sub-branch I of the Tupí-Guaraní family, according to Rodrigues (1984/1985). It is, therefore, a study of the morphosyntactic description of nouns in that language. The analysis based primarily on Rodrigues (2001), but we also approach and feel contemplated with the ideas of Payne (1997). In this text, therefore, there is a description of the syntactic properties of nouns that occur in function of predicate nucleus. The look given to the question enabled us to describe existential, equative and attributive predicates, expanding our knowledge about these phenomena through the linguistic analysis of a variety of the Kaiowá language spoken in the southern cone of Mato Grosso do Sul. We believe that the results can be compared with other Tupí-Guaraní languages in order to seek possible explanations of changes within the family and to identify what has been preserved in this aspect.
\end{abstract}

KEYWORDS: Tupí-Guaraní Family. Kaiowá language. Nominal Predicates

\footnotetext{
*Doutor em Linguística e Professor do Programa de Pós-Graduação em Letras da Faculdade de Comunicação, Artes e Letras da Universidade Federal da Grande Dourados (PPG Letras/FACALE/UFGD). E-mail: anderbiomartins@ufgd.edu.br.

*** Mestra em Letras pelo PPG Letras/FACALE/UFGD. E-mail: liviarviegas@hotmail.com
} 


\section{Introdução}

Neste trabalho apresentamos uma proposta de descrição das propriedades sintáticas dos nomes como núcleos de predicado na língua Kaiowá. A presente discussão acerca dos predicados nominais em Kaiowá é parte do resultado da dissertação de mestrado defendida em julho de 2017 sob o título "Nomes e Predicados Nominais em Kaiowá" (VIEGAS, 2017), no Programa de Pós-Graduação em Letras da Universidade Federal da Grande Dourados (PPG Letras/UFGD).

Para tornar evidente que há nomes em Kaiowá que predicam, baseamo-nos na lógica de análise apresentada e defendida por Rodrigues (1996, 2001), conscientes de que suas ideias também sejam compartilhadas por outros especialistas ${ }^{1}$ em línguas indígenas brasileiras, como Ana Suelly Arruda Câmara Cabral, Doutora em Linguística, professora do Programa de Pós-Graduação em Linguística da Universidade de Brasília e coordenadora do Laboratório de Línguas e Literaturas Indígenas da Universidade de Brasília (LALLI/UnB), além de Sanderson Castro Soares de Oliveira, professor da Universidade Federal do Amazonas, ambos conhecedores de línguas Tupí-Guaraní, sendo Cabral, provavelmente, a maior especialista de línguas indígenas brasileiras na atualidade, com profundo conhecimento linguístico de descrição, análise e comparação de línguas, além de estar em contato contínuo com várias delas em seu ambiente de trabalho, seu principal meio de convívio social com indígenas de diversas etnias.

Além disso, contamos com o conhecimento linguístico adquirido nas formações pelas quais passamos e pelo contato contínuo que temos com essa língua dentro da Licenciatura Intercultural Indígena - Teko Arandu, curso lotado na Faculdade Intercultural Indígena da Universidade Federal da Grande Dourados, localizada no município de Dourados, onde estamos no raio de $300 \mathrm{~km}$ da área indígena guarani e kaiowá mais distante e a $4 \mathrm{~km}$ da mais próxima. No curso, interagimos com indígenas da etnia Kaiowá tanto nos tempos de aulas presenciais na Universidade quanto nas

\footnotetext{
${ }^{1}$ Os especialistas citados foram membros da banca de defesa da dissertação de mestrado realizada em julho de 2017, defendida no Programa de Pós-Graduação em Letras da Universidade Federal da Grande Dourados.
} 
próprias áreas indígenas, por meio dos atendimentos pedagógicos que ocorrem, no que denominamos tempo comunidade de formação.

Os trabalhos de Rodrigues $(1996,2001)$ foram de suma importância para nos esclarecer sobre o fenômeno descrito e para compreender melhor a análise que Cardoso realizou em sua tese de doutorado no ano de 2008, no Programa de Pós-Graduação em Linguística do Instituto de Estudos de Linguagem da Universidade Estadual de Campinas, a fim de que pudéssemos, aliado ao conhecimento que temos da língua, empreender uma revisão do que sabemos sobre predicados nominais em Kaiowá. Diante disso, um estudo mais responsável para compreender predicados nominais, de maneira mais geral, foi também necessário, por isso consideramos em nossa leitura as ideias apresentadas por Payne (1997) e Dixon (2010).

Como sabemos, a língua Kaiowá é um membro do sub-ramo I da família TupíGuaraní, conforme Rodrigues (1984/1985). Essa família se destaca pela sua grande extensão territorial, pois suas línguas ocupam boa parte da América do Sul (Brasil,Paraguai, Argentina, Bolívia e Guiana Francesa). Cabe destacar que, além da língua Kaiowá, fazem parte do sub-ramo I da família o Nandéva (Txiripá), o Mbyá, o Guarani Antigo, o Xetá, o Guarani Paraguaio, o Guayakí (Aché), o Tapieté, o Chiriguano (Avá) e o Izocenõ (Chané) (idem).

O Kaiowá é umas das línguas da família Tupí-Guaraní com um maior número de falantes no Brasil, são cerca de 43.400 conforme dados do IBGE (2010). Também é falada no Paraguai, onde é conhecida pelo nome de Pãi ou Pãi-Tavyterã que, conforme o III Censo Nacional Indígena do Paraguai, em 2012, somava-se aproximadamente 15.494 indivíduos (DGEEC, 2012).

No Brasil, atualmente, as terras tradicionalmente Kaiowá estão localizadas no sul do estado de Mato Grosso do Sul. O povo está distribuído juntamente com o povo guarani, em sua maior parte, em 6 das oito reservas demarcadas pelo SPI no período de 1915 a 1928: Terra Indígena Amambai e T.I. Limão Verde (ambas situadas no município de Amambai); T.I. Francisco Horta Barboza, município de Dourados (aqui junto com Guarani e Terena, distribuídos em duas aldeias: Bororó e Jaguapiru); T.I. Te'ýikue (junto com Guarani, município de Caarapó); T.I. Taquaperi no município de Coronel Sapucaia; T.I. Sassoró, município de Tacuru. Também se encontram em aldeias como Panambi (município de Douradina) e Panambizinho (município de Dourados)- 
trata-se de terras retomadas e homologadas posteriormente à promulgação da Constituição Federal de 1988 (CAVALCANTE, 2013, p. 89).

Para além dessas áreas, outros tekoha kwéra (lugares de viver) foram sendo constituídos por indígenas que resistiam a viver nas reservas criadas pelo SPI. Atualmente são conhecidas como tekoha Takuaraty-Yvykuarusu (Paraguasu), município de Paranhos; tekoha Rancho Jacaré, município de Laguna Carapã; tekoha Pirakua, município de Bela Vista; tekoha Yvy Marangatu (aldeia Campestre), município de Antônio João; tekoha Jaguapiré, município de Tacuru; tekoha Jaguari, município de Amambai; tekoha Jarara, município de Juti; tekoha Guasuti, município de Aral Moreira e tekoha Sete Cerros, município de Coronel Sapucaia (CHAMORRO, 2015, p. 208214).

Para apresentarmos os predicados nominais em Kaiowá, adotamos a seguinte organização neste artigo: deixamos claro o que sabemos e do que precisamos saber sobre Predicados Nominais a partir de Payne (1997). Em seguida, apresentamos a nossa interpretação sobre o que compreendemos em Cardoso (2008) acerca desse aspecto e; reproduzimos, de forma breve, a descrição de predicados nominais para o Tupinambá elaborada por Rodrigues (2001). Por fim, apresentamos a nossa proposta de descrição de predicados nominais em Kaiowá, considerando as reflexões que fizemos e as conclusões a que chegamos, até o dado momento, sobre o fenômeno analisado.

Os dados apresentados são provenientes de trabalhos de campo realizado pelos autores na Terra Indígena Panambizinho, Dourados-MS e na Faculdade Intercultural Indígena - FAIND com os professores indígenas em formação. Cabe destacar que tivemos também acesso a dados do Kaiowá falados em Campestre, localizada no município de Antônio João-MS.

\section{Predicados nominais}

Iniciamos nossa discussão sobre predicados nominais com base nos estudos de Payne (1997). Para o autor (1997, p. 111), as sentenças que expressam inclusão, equação, atribuição, locação, existência e posse, nas quais o conteúdo semântico é expresso por um nome, são chamados de predicados nominais. Sendo que, as construções existenciais predicam a existência de alguma entidade, geralmente em 
algum local especificado; as construções locacionais predicam locação/lugar; e as sentenças possessivas predicam posse.

Além disso, em sua maneira de olhar para o fenômeno que ocorre em diversas línguas, os predicados nominais expressam duas noções: de inclusão e equação. Na inclusão, o sujeito da oração é específico e o predicado nominal é um não-específico. Nas sentenças equativas o sujeito da oração é idêntico à entidade especificada no predicado nominal.

\section{Predicados nominais em Kaiowá e em Tupinambá - breves apontamentos}

Para iniciarmos a discussão sobre predicados nominais em Kaiowá, cabe ressaltar a importância dos trabalhos pioneiros realizados com objetivos unicamente acadêmicos e a serviço do povo indígena kaiowá realizados pela professora Doutora Valéria Faria Cardoso, que escreveu, entre diversos outros trabalhos, uma tese de doutorado, considerando os aspectos morfossintáticos da língua Kaiowá. Trata-se do primeiro trabalho linguístico que apresenta maiores detalhes sobre a forma de funcionamento dessa língua, superando, inclusive, o que já sabíamos por meio de trabalhos anteriores, empreendidos por linguistas-missionários do Summer Institute of Linguistics (SIL) nas décadas de 1950, 1960, 1970 e 1980, mas que ainda hoje recorremos, pois são descrições com um nível de precisão seguro do Kaiowá falado pelos mais velhos de todas essas décadas, o que provavelmente encontra-se na Bíblia Sagrada traduzida em Kaiowá, publicada em 2013 na sua totalidade.

No entanto, estudos linguísticos atuais têm demonstrado que as propostas de explicações anteriores para alguns aspectos gramaticais dessa língua já não condizem com nossa nova forma de compreendê-la, devido principalmente ao avanço dos conhecimentos linguísticos que obtivemos nas últimas décadas, sobretudo das línguas indígenas brasileiras, empreendidas por pesquisadores que tentavam, e ainda tentam, desvendar a fascinante lógica de funcionamento desses sistemas, sem afetar sobremaneira a estrutura social e cultural que as compõem e pelo qual e no qual existem. Por essa lógica de raciocínio, optamos inicialmente por compreender o funcionamento dos predicados nominais em Kaiowá a partir do olhar de Cardoso 
(2008). Neste artigo, colocamos em evidência a que conclusões chegou a pesquisadora sobre o fenômeno analisado. Em seguida, apresentamos as reflexões também realizadas por Rodrigues quando imprimiu uma proposta de descrição acerca dos predicados nominais da língua Tupinambá.

Em Kaiowá, Cardoso (2008, p. 130) define os predicados nominais (não-verbais) como “aqueles cujos núcleos não são constituídos por verbos, e estabelecem relações de posse, identidade e locação". A pesquisadora apresenta os três tipos de predicados nominais em Kaiowá: possessivo, equativo e locativo e tece as seguintes afirmações:

(a) nos predicados possessivos, o núcleo é um nome que estabelece uma relação de posse com outro nome ou pronome na função de um argumento;

(b) os predicados equativos estabelecem uma relação de identidade, o argumento do sintagma nominal é idêntico à entidade especificada no predicado nominal;

(c) as orações com predicados locativos são orações constituídas por um sintagma nominal em função do sujeito e de um núcleo adverbial em função do predicado;

(d) essas orações, por fim, são negadas por meio do morfema descontínuo de negação $\{$ na- ... -i $\}$ que, em geral, negam predicados.

Cabe destacar que Cardoso (2008) considera a existência de verbos intransitivos inativos a partir de um conjunto de palavras que, em seu modo de ver a língua, recebem marcasde categoria de pessoa, o que se dá por meio do que passou a considerar em seu estudo como pronomes clíticos da série II (che, nde, nhande, ore, pende). Para a pesquisadora, esse tipo de estrutura se assemelha ao que se identifica na relação objeto/verbo transitivo na língua. Compreende-se também que essa subcategoria verbal foi motivada pelo fato de que esse conjunto de palavras (supostos verbos intransitivos inativos) não ocorrem com prefixos da série I e III (a-, re-, o-, ro-, ja-, pe-, (o)ro- e (o)po-); passando a ter, portanto, um argumento em nível morfológico para sustentar sua análise e sua proposta de descrição.

Em sua tese, Cardoso (2008) afirma que os verbos intransitivos inativos recebem um argumento apenas, o sujeito. Este argumento externo, como mencionado, vem marcado por pronomes clíticos da série II e prefixos relacionais ${ }^{2}$. Essas palavras

\footnotetext{
2 Sobre prefixos relacionais em Kaiowá, ver Martins; Cabral; Viegas e Mejia (2017). A referência completa encontra-se no fim deste artigo, junto com as demais utilizadas.
} 
constituem predicados e possuem propriedades semânticas de estado, atributo ou qualidade, condição, etc. Sobre esses aspectos, a pesquisadora considera como verbos intransitivos inativos em Kaiowá os seguintes: rasẽ 'chorar', porã 'ser bom', ri'anhu 'estar madura', entre outros.

Já em Tupinambá, Rodrigues (2001) descreve os predicados nominais identificados partindo do princípio de que nomes também predicam, ou seja, nomes podem funcionar como núcleos de predicado, além de possuir, em outros momentos, função argumental e circunstancial. A partir disso, e analisando os dados disponíveis do Tupinambá, Rodrigues chega à seguinte classificação de predicados nominais existentes nessa língua: Predicados Existenciais, Predicados Possessivos e Predicados Equativos.

De acordo com sua análise, os predicados existenciais em Tupinambá são expressos pelo nome sem caso argumentativo (índice nominal), conforme o exemplo abaixo:

(1) aó

roupa

'há roupas'

Sobre os predicados possessivos, Rodrigues (2001, p. 111) afirma que "estes são expressos pela sequência de um nome no caso argumentativo, o qual é o sujeito, e outro nome sem caso, o qual é o predicado". Conforme exemplo:

(2) sjé aríj -a s- ekújpé $\beta$

1 avó ARG $\mathrm{R}^{2}$ cuia.rasa

'minha avó tem uma cuia rasa'

Rodrigues (2001, p. 111) afirma que os nomes de qualidade ou atributos, quando predicados, também são construídos possessivamente, e os classifica como predicados atributivos: 
(3) sjé aríj -a s- orí $\beta$

1 avó $\mathrm{ARG} \mathrm{R}^{2}$ estar alegre

'minha avó tem alegria' minha avó está alegre'

Para Rodrigues (2001, p. 111), os predicados equativos expressam uma equação entre dois argumentos, e têm por núcleo um nome no caso argumentativo, o qual normalmente precede o sujeito (igualmente no argumentativo), mas também pode seguilo com pequena pausa interposta. Como exemplos de predicados equativos, o pesquisador apresenta:

(4) kó apiá $\beta$-a sjé r- ú $\beta$-a

este homem ARG 1 R $\mathrm{R}^{1}$ pai ARG

'meu pai é este homem'

(5) Iporose’õ sjé r-éra

Iporose'õ $1 \quad \mathrm{R}^{1}$ nome

'meu nome é Iporose'õ'

\section{Predicados nominais em Kaiowá - uma proposta de descrição}

Após verificarmos que Cardoso (2008) assumiu a proposta de considerar como verbo o que Rodrigues classificou como nome, analisamos as duas possibilidades de descrição da seguinte forma: se considerarmos como verbo, estaríamos olhando apenas a sua estrutura argumental, como fez Cardoso; se considerarmos como nome, estaríamos olhando a sua morfologia, uma vez que não ocorre com prefixos pessoais; morfemas intrinsecamente ligados a temas verbais. Além disso, também estaríamos olhando para a sua estrutura argumental, considerando o que os estudos tipológicos não têm posto em dúvida, que é a existência de nomes que predicam, que possuem uma estrutura argumental semelhante ao verbo, quando ocupa o núcleo do predicado, comportando-se como um verbo intransitivo, tendo em vista a exigência de preencher na estrutura argumental apenas uma posição, a de sujeito. 
Com base nesses dois caminhos, optamos descrever os predicados nominais do Kaiowá em conformidade com Rodrigues $(1996,2001)$, pois nos parece a proposta mais adequada para uma divisão discreta entre nomes e verbos, que é o fato de considerar como verbos apenas os temas que recebem prefixos pessoais; critério seguido, inclusive, por Mejia (2017), em seu estudo sobre a descrição morfológica dos verbos em Kaiowá. Além, é claro, de admitir que nomes podem assumir a função de núcleo de predicado, o que sustenta o nosso conhecimento sobre o fato de que há línguas em que nomes podem ocupar em determinada estrutura tanto a posição de argumento quanto núcleo de predicado, assim como pode ser visto em Dixon (2010), quando explica a distinção entre a classes de nomes e a classe de verbos. $\mathrm{O}$ mesmo autor apresenta funções não canônica s para cada uma delas. Dentro dessa perspectiva, apresentamos nossa proposta de compreensão dos predicados nominais em Kaiowá, até o presente momento. Cabe destacar que, como houve a perda do caso argumentativo nessa língua (VIEGAS, 2017), passou a ser necessário acionar outros mecanismos para garantir a existência de predicados com valor existencial. Nesse caso, tem sido utilizado o verbo -ime 'estar em pé' na construção do enunciado:

(6) o- ime petei ${ }^{3}$ óy

3- estar.em.pé uma casa

'há uma casa'

(7) o- ime peteĩ cachorro 'ápy

3- estar.em.pé um cachorro aqui

'há um cachorro aqui'

(8) o- ime peteĩ mbo'e r- óy t- eko -ha -py

3- estar.em.pé um ensinar $\mathrm{R}^{1}$ casa $\mathrm{R}^{4}$ estar.em.movimento CIRC LP

'há uma escola na aldeia'

\footnotetext{
${ }^{3}$ Aqui a palavra comumente usada para se referir a unidade 1 na linguagem matemática, passou também a ser interpretada como um artigo indefinido, semelhante ao que temos em português. É possível que essa estrutura particular para a construção de um predicado nominal existencial em Kaiowá (usando um verbo) seja também influência do português.
} 
Em predicados negados, verificamos que o nome continua sendo o núcleo do predicado existencial, o que revela que a negação preserva estruturas mais conservadoras na língua ${ }^{4}$.

$\begin{array}{lllll}\text { (9a) } & \text { nd }= & \varnothing- & \text { Óy } & \text {-ri } \\ & \text { não } & \mathrm{R}^{4} & \text { Casa } & \text { NEG } \\ \text { 'não existe casa' } & \\ & & & & \\ \text { (9b) nda }= & \text { h- } & \text { Óy } & \text {-ri } \\ & \text { Não } & \mathrm{R}^{2} & \text { Casa } & \text { NEG } \\ & \text { 'não existe a casa dele' }\end{array}$

Em Kaiowá, os predicados possessivos apresentam o verbo -reko'ter' (rC.COM + eko 'estar em movimento') como núcleo dos predicados que expressam semanticamente essa relação.

$$
\begin{array}{llllll}
\text { xe } & \text { a- } & \text { r- } & \text { eko } & \text { mitã } & \text { kwimba’e } \\
1 & 1 & \text { C.COM } & \text { estar.em.movimento } & \text { criança } & \text { Homem }
\end{array}
$$

'eu tenho filho'
(11) xe a-
r- eko
o- Memby
kwimba'e
11
C.COM estar.em.movimento
$\mathrm{R}^{3} \quad$ filho.da.mulher homem
'eu tenho filho'
(12)

$$
\begin{array}{llll}
\text { nda }= & \text { xe } & \text { memby } & \text {-ri } \\
\text { Não } & 1 & \text { filho.da.mulher } & \text { NEG } \\
\text { 'não tenho filho' } &
\end{array}
$$

Em Kaiowá, nomes de ação e nomes atributivos constituem predicados nominais atributivos e existenciais.

\footnotetext{
${ }^{4}$ Sobre a negação, diferentemente do que interpreta Cardoso, consideramos o morfema nda como uma expressão de negação cliticizada ao verbo, sendo a flexão de negação do predicado o sufixo -i.
} 
(13) xe xe Ø- porã

$11 \mathrm{R}^{1}$ bom

'sou bom'

(14) xe xe Ø- vai

$1 \quad 1 \mathrm{R}^{1} \mathrm{mau}$

'sou mau'

(15) xe Ø- mandua Maria $r-$ ehe

$1 \quad \mathrm{R}^{1}$ lembrar Maria $\mathrm{R}^{1}$ REL

'existe a minha lembrança em respeito à Maria / eu me lembro de Maria'

(16) xe r- esarái Maria Ø- gwi

$1 \quad \mathrm{R}^{1}$ esquecer Maria $\mathrm{R}^{1} \quad \mathrm{ABL}$

'existe o meu esquecimento afastando-me de Maria / eu me esqueci da Maria'

Predicados Equativos em Kaiowá:

(17) xe i- túva

$1 \quad \mathrm{R}^{2}$ pai

'eu sou pai dele'

(18) xe ha' $e^{5}$ i- sy

1 Este $\mathrm{R}^{2}$ mãe

'eu sou mãe dele'

(19) xe i- mbo'ehára

$1 \mathrm{R}^{2}$ professor

'eu sou professor dele'

\footnotetext{
${ }^{5}$ Embora não seja muito comum na fala de Kaiowá de áreas mais tradicionais, em algumas situações tem sido utilizado o demonstrativo ha'e como uma espécie de cópula. Temos a impressão de que esse tipo de uso é mais frequente no Guarani Ñandéva e no Guarani Paraguaio, línguas com as quais os Kaiowá também estão em contato.
} 
(20)

xe ha'e i- mbo'ehára

1 Este $\mathrm{R}^{2}$ professor

'eu sou professor dele'

(21) xe Ø- mbo'ehára

$1 \mathrm{R}^{1}$ professor

'eu sou professor'

(22) Ore Ø- mbo'ehára kwéry

1pl.excl. $\quad \mathrm{R}^{1}$ professor $\mathrm{COL}$

'nós (exclusivo) somos professores

\section{Considerações finais}

Neste trabalho, apresentamos os tipos de predicados nominais em Kaiowá identificados a partir dos dados disponíveis. Buscamos seguir a classificação utilizada por Rodrigues (2001) para o Tupinambá, sendo, portanto: Predicados Existenciais, Predicados Possessivos e Predicados Equativos. Vimos que, com a perda do Caso Argumentativo, a língua Kaiowá desenvolveu mecanismos para continuar utilizando nomes em sua função prototípica na estrutura, em função argumental; e também como núcleos de predicado.

Com a descrição dos predicados nominais em Kaiowá, esperamos contribuir com a difusão do conhecimento de aspectos linguísticos dessa língua falada na região sul de Mato Grosso do Sul para fins científicos e escolares. Enquanto isso, continuaremos dando prosseguimento ao trabalho de documentação, análise e descrição linguística desta língua, buscando também auxiliar professores Guarani e Kaiowá que estão diretamente envolvidos no ensino de sua língua materna nas escolas das aldeias. 


\section{REFERÊNCIAS}

CARDOSO, V. F. Aspectos morfossintáticos da Língua Kaiowá (Guarani). Tese (Doutorado) - Universidade Estadual de Campinas, Instituto de Estudos da Linguagem, Campinas, SP: [s.n.], 2008.

CAVALCANTE, Thiago Leandro Vieira. Colonialismo, território e territorialidade: a luta pela terra dos Guarani e Kaiowá em Mato Grosso do Sul. Tese de Doutorado. São Paulo: Faculdade de Ciências e Letras de Assis, Universidade Estadual Paulista, 2013.

CHAMORRO, Graciela. História Kaiowá: das origens aos desafios contemporâneos. São Bernardo do Campo: Editora Nhanduti, 2015.

DIRECCIÓN GENEREAL DE ESTATÍSTICAS, ENCUSTAS Y CENSOS (DGEEC). Memoria del II Censo Nacional de Población y Viviendas. Asunción: STP-DGEEC, 2002.

DIXON, R.M.W. Basic Linguistic Theory. New York: Oxford University Press, 2010, Vol. 2. Grammatical Topics.

MEJIA, B. F. D. Verbos em Kaiowá: uma descrição morfológica. Dissertação de Mestrado. Programa de Pós-Graduação em Letras da Universidade Federal da Grande Dourados. Dourados: UFGD, 2017.

PAYNE, T. Describing morphosyntax: a guide for fiel linguistic. Cambridge: Cambridge University Press, 1997.

RODRIGUES, Aryon Dall'Igna. Relações internas na família linguística Tupi-Guarani. In: Revista de Antropologia, separata dos volumes XXXVII/XXVIII. São Paulo, 1984/1985.

. Sobre a natureza do caso argumentativo. In: F. Queixalós. (Org.). Des noms et des verbes en tupi-guarani: état de la question. Munique: LINCOM Europa, 2001, p. 103-114. 
. Argumento e Predicado em Tupinambá. Boletim da ABRALIN, n. 19, p. 5766, 1996. Republicado na Revista de Linguística Antropológica, v. 3, n.1 (Jul. 2011) Brasília: Laboratório de Línguas Indígenas, Instituto de Letras, Universidade de Brasília, 2011, p. 93-102. Aryon Dall'Igna Rodrigues (editor), Ana Suelly Arruda Câmara Cabral (co-editora).

VIEGAS, L. R. Nomes e Predicados Nominais em Kaiowá. Dissertação de Mestrado. Programa de Pós-Graduação em Letras da Universidade Federal da Grande Dourados. Dourados: UFGD, 2017. 